\title{
Recurrent Head and Neck Carcinoma
}

National Cancer Institute

\section{Source}

National Cancer Institute. Recurrent Head and Neck Carcinoma. NCI Thesaurus. Code C7624.

The reemergence of carcinoma in the head and neck region after a period of remission. 